\title{
Transformation Measures on the Phenomenon of "Marginal Man" in Primary School Classroom Teaching
}

Yu Shen

Zhejiang Normal University (Teaching school in Jinhua Vocational and Technical College) ， Jinhua 321000, China E-mail: 602006592@qq.com

Abstract: "Marginal man" in classroom teaching activities is a special group which doesn't be accepted by teachers and other students meanwhile has a poor development on physical and mental health because of various reasons away from teaching activities. Curriculum revolution requires teaching staff should pay more attention to "marginal man" in class and think highly of their development. Therefore the class will be vitalized positively. Starting with the following three aspects, teacher, student and family, they will feel the education of love and become the real master of class gradually.

Keywords: Primary School; Classroom Teaching; Marginal Man; Transformation Measures; Learning Motivation

\section{Background and present situation}

Outline for the Reform of Basic Education Curriculum(Trial Implementation) pointed out, "The key point is to a proactive learning attitude. " and "advocate students to participate actively, explore readily and start work diligently, develop students' abilities to collect and process information, acquire knowledge, analyze and solve problem and communicate and cooperate ${ }^{[1]}$. "Curriculum Revolution requires teaching staff should pay more attention to "marginal man" in class, think highly of their development and improve teaching quality. Therefore the class will be vitalized positively and education equality will be really achieved in the future. In recent years with the attention of society and teaching staff to this group, related research and literature begin to increase ${ }^{[2]}$. However the amount is less. The special group is still in the inferior place and its improving measures as well as developing condition are worthy of considering and worrying.

\section{Factors affecting "marginal man" in primary school classroom teaching}

In this article, "marginal man" in classroom teaching activities is a special group which doesn't be accepted by teachers and other students meanwhile has a poor development on physical and mental health because of various reasons away from teaching activities. There has a lot of factors influencing "marginal man", but the main factors are three aspects $^{[3]}$.

\subsection{Teachers' professional qualities}

The teachers' professional qualities are consisted of professional sentiments and norms, professional knowledge and competence. Professional ethics is one of the important factors to measuring the formation and maturity of teachers' professional ${ }^{[4]}$. For example, some teachers will have a bad moral performance including treating students with prejudice, preferring students with excellent grades, ignoring students with bad grades, leaving better seats for outstanding students and so on. To some extent, it strikes students' learning initiative meanwhile students will be lack of encourage and support in the long time, causing students away from the classroom center even to be "marginal man".

Copyright $\odot 2020$ Yu Shen

doi: $10.18282 /$ le.v9i7.1471

This is an open-access article distributed under the terms of the Creative Commons Attribution Non-Commercial License

(http://creativecommons.org/licenses/by-nc/4.0/), which permits unrestricted non-commercial use, distribution, and reproduction in any medium, provided the original work is properly cited. 


\subsection{Students themselves and learning motivation}

Students are unique. The most essential feature of uniqueness is individuality which means differences and integrity. It influences students' performances in class to a great extent. Students who belong to bilious temperament and sanguineous temperament are integrated into the classroom easily and perform actively. lymphatic temperament is apt to perform quietly and steadily meanwhile melancholic temperament which is sensitive and unsocial is lack of confidence more. In addition, learning motivation will play a suggestive role at the psychological level[5]. Good learning motivation can activate, guide, maintain and adjust, which helps students to integrate into the classroom as well as accomplish the goal. David Pawl Ausubo thought that learning achievement motivation can be divided into three categories, cognitive drive, self-improvement drive and affiliated drive. During the primary school period, affiliated drive which belongs to external drive is predominant. If students are not supported and encouraged by teachers and parents, their motivation level will be lowed which affecting learning outcomes and goals. Moreover, different subjects differ. If some students are interested in math, their learning motivation will be strong. Otherwise, they will away from the classroom center[6].

\subsection{Home education and class culture}

Environment can be divided into two categories, natural environment and social environment. The latter will play the vital role in human development. For the pupil, they are home environment and class culture environment. The famous educator $\mathrm{H} \mathrm{ад} \mathrm{де} \mathrm{д} \mathrm{а} \mathrm{К} \mathrm{о} \mathrm{н} \mathrm{с} \mathrm{т} \mathrm{а} \mathrm{н} \mathrm{т} \mathrm{и} \mathrm{н} \mathrm{о} \mathrm{в} \mathrm{н} \mathrm{а} \mathrm{К} \mathrm{р} \mathrm{у} \mathrm{п} \mathrm{у} \mathrm{с} \mathrm{к} \mathrm{а} \mathrm{я} \mathrm{thought,} \mathrm{"Parents} \mathrm{are} \mathrm{natu-}$ ral teachers for children, which have the greatest impact on children. "The knowledge level and educational concepts of parents will have a profound influence to children[7]. Therefore, some factors, for example, false educational concepts, unharmonious patterns and parents' indifference will result in students freeing from classroom center even not integrating into classroom teaching. Besides, class culture effects students virtually. Positive class culture, which is invisible curriculum resources and the vane of class construction, will play the role of condensing orientation. In contrast, negative class culture is just a heap of loose sand which accelerating the marginalization of students[8].

\section{Transformation measures of "marginal man" in primary school classroom teaching}

"marginal students" has three features, marginality, vulnerability and mutability. In primary classroom, "marginal students" is a neglected group and will suffer more problems and challenges in their development because of various reasons. So more attention should be payed to this group, then they will feel the education of love, which promotes students to be the real master of classroom teaching. In response to these factors' influence, transformation measures start with following three aspects, teacher, student and family.

\subsection{Enhancing professional qualities and having a positive interaction between teachers and students}

For the primary students, teachers' behaviors will influence students' development imperceptibly. The process is secular and dynamic meanwhile its effect will last for a long time. Therefore, teachers should learn new knowledge continuously to reach the goal of outstanding professional. Furthermore, teachers should abide professional ethics. Above all, "love" and "responsibility" will exist in teachers' lifetime. Teachers ought to give equal treatment to all students in class teaching management with more encouragement instead of denial and take full notice of students' development which means varied evaluation modalities should be taken to measure students instead of the single index of scores. Accordingly, a positive interaction between teachers and students will be formed in class meanwhile teachers will understand, love and integrate into students in deed.

\subsection{Teaching students in accordance with their aptitude as well as subjects and motivating learning motivation}

Skinner's reinforcement theory holds that a person's learning behavior tendency depends on the firm relationship between the learning behavior and the stimulation and response established by the reinforcement. Therefore, teachers should increase positive reinforcement effectively and take advantage of negative reinforcement reasonably for the students lack of confidence to motivate their learning motivation. And their learning behaviors and results will be im- 
proved greatly. At the same time, three points should be noticed carefully[9]. The first point is to set clear, concrete and appropriate learning goals. The second point is that the feedback of learning results should be timely and give positive and pertinent evaluation to students. The last is to motivate students' inner learning motivation by using rewards and punishments rationally. Maslow's hierarchy of needs theory holds that students' lack of learning motivation may be caused by some lack of satisfaction. For students who perform unsociable and eccentric, teachers should not only take the initiative to help, attach importance to and allow for the students in their studies, but also meet the students' lack needs in life and emotion. In this way, students will feel the respect and care of teachers. For students who have short board in subjects, teachers should cultivate and strengthen students' self-efficacy first, then help students to build meaningful learning which is non-human, substantive connections instead of simple mechanical learning[10].

\subsection{Optimizing class management and promoting the communication and cooperation of school and home}

The development of students is close relevant to class teachers' working attitude and capacity of management. Scientific and effective measures should be taken by teachers and pay close attention to every students as much as possible. Consequently, it will optimize class management, improve the quality of class management and achieve the development of class. Only good class management can form outstanding class culture and it will be the real vane to guide students' all-round development. Simultaneously, class teachers need to understand every student's family background, and share their children's performances in good season with various communication ways. Especially for students whose families are in difficulties, they need more care and considerations. Only parents and schools are of one heart, students can enjoy study and classroom authentically rather than "marginal man".

\section{References}

1. Wu Jin, Jia Lishuai. "Marginalized People" in primary School Classroom Teaching and its Transformation [J].Teaching and Management, 2015(32):1-3.

2. Zheng Zhangping. Research on "Marginal Students" in Primary School Classrooms [D]. Hubei University, 2016.

3. Wu Yan. Neglected "Marginal Man” [D]. Shenyang Normal University, 2018.

4. Qi Yuhui, Li Sen. On the Formation process and Coping Strategies of Marginal People in classroom Teaching [J]. Education Science, 2014, 30(02):32-37.

5. Zhang Yan. Discussion on How to do a good job in class Management of Primary School Class Teachers [J]. Electronic Journal of New Education Times (Teacher edition), 2020, (4):12.

6. Zhu Hong, Lu Lili. Discussion on The Innovation and Practice of Class Management of Primary School Headteacher [J].China Youth, 2017(10):269-270.

7. Yao Li. "Liangjian" : Loopholes under the Sun -- An Introduction to the Study of Self-consciousness of Students on the Edge of Contemporary Primary School Teaching [J].Intelligence, 2016 (35) : 208-209.

8. Zhou Qingxia. Case Study of "Marginal Person" phenomenon in primary School Mathematics Classroom Teaching Participation [D].Sichuan Normal University, 2017.

9. Xu Kaifang. Research on the Discourse Power of "Marginalized people" in Classroom Teaching [D].Bohai University, 2018.

10. Qi Yuhui. Research on the Phenomenon of "Marginal Man" in Classroom Teaching [D]. Southwest University, 2014. 